\title{
Direct oral anticoagulants for extended thromboprophylaxis in medically ill patients: meta-analysis and risk/benefit assessment
}

This article was published in the following Dove Press journal:

Journal of Blood Medicine

\author{
Majed S AI Yami ${ }^{1,2}$ \\ Sawsan Kurdi ${ }^{2,3}$ \\ Ivo Abraham ${ }^{2,4,5}$
}

'Department of Pharmacy Practice, King Saud bin Abdulaziz University for Health Sciences, Riyadh, Saudi Arabia; ${ }^{2}$ Center for Health Outcomes and PharmacoEconomic Research, University of Arizona, Tucson, AZ, USA; ${ }^{3}$ Department of Pharmacy Practice, University of Dammam, Dammam, Saudi Arabia; ${ }^{4}$ Department of Pharmacy Practice and Science, College of Pharmacy, University of Arizona, Tucson, AZ, USA; ${ }^{5}$ Department of Family and Community Medicine, College of Medicine, University of Arizona, Tucson, AZ, USA
Correspondence: Ivo Abraham Center for Health Outcomes and PharmacoEconomic Research, University of Arizona, 1295 N. Martin, P.O. Box 210202, Tucson, AZ 8572I-0202, USA $\mathrm{Tel}+\mathrm{I} 5206264425$

Fax +I 5206262023

Email abraham@pharmacy.arizona.edu
Background: Standard-duration (7-10 days) thromboprophylaxis with low molecular weight heparin, low dose unfractionated heparin, or fondaparinux in hospitalized medically ill patients is associated with $\sim 50 \%$ reduction in venous thromboembolism (VTE) risk. However, these patients remain at high risk for VTE post-discharge. The direct oral anticoagulants (DOACs) apixaban, rivaroxaban and betrixaban have been evaluated for extended-duration (30-42 days) thromboprophylaxis in this population.

Methods: We review the efficacy and safety results from the 3 pivotal trials of extended-duration DOAC thromboprophylaxis in medically ill patients. We performed a meta-analysis of these pivotal trials focusing on 6 VTE (efficacy) and three bleeding outcomes (safety). These results were integrated into a quantitative risk/benefit assessment.

Results: The trials evaluating extended-duration DOAC thromboprophylaxis in medically ill patients failed to establish clear efficacy and/or safety signals for each agent. Our meta-analysis shows that, as a class, DOACs have selective and partial extended-duration prophylactic activity in preventing VTE events. However, this is associated with a marked increase in the risk of various bleeding events. The risk/benefit analyses fail to show a consistent net clinical benefit of extended-duration DOAC prophylaxis in medically ill patients.

Conclusion: At this time, the evidence of safe and effective extended-duration thromboprophylaxis with DOACs in this population is inconclusive.

Keywords: venous thromboembolism, direct oral anticoagulants, enoxaparin, thromboprophylaxis, medically ill patients

\section{Introduction}

Venous thromboembolism (VTE), which includes deep vein thrombosis (DVT) and pulmonary embolism (PE), is among the most preventable vascular conditions. ${ }^{1}$ Even if medically ill patients receive the recommended 7-10 days of thromboprophylaxis during their hospitalization, they remain at increased risk of developing VTE after hospital discharge. ${ }^{2}$ The 2012 American College of Chest Physicians (ACCP) guidelines support the use of such anticoagulants as low molecular-weight heparin (LMWH), unfractionated heparin (UFH), and fondaparinux for short-duration pharmacologic thromboprophylaxis in hospitalized medically ill patients. ${ }^{3}$ On the other hand, these guidelines also advise against extended-duration thromboprophylaxis (up to 30 days post-discharge) beyond the period of patient immobilization or acute hospital stay for patients who received an initial course of thromboprophylaxis. ${ }^{3}$

The ACCP recommendations were based on the results from the EXCLAIM trial ${ }^{4}$ in hospitalized medically ill patients. In this study, extended-duration thromboprophy- 
laxis with the LMWH enoxaparin versus placebo reduced the incidence of VTE in general (absolute risk difference $[\mathrm{RD}]=-1.53 \%, 95 \% \mathrm{CI}:-2.54 \%$ to $-0.52 \%$ ) but not the incidence of PE events overall $(\mathrm{RD}=-0.16 \%, 95 \% \mathrm{CI}:-0.34 \%$ to $0.04 \%$ ), fatal $\mathrm{PE}$ events $(\mathrm{RD}=-0.04 \%, 95 \% \mathrm{CI}:-0.12 \%$ to $0.04 \%$ ), and overall mortality (hazard ratio $=0.93 \%, 95 \% \mathrm{CI}$ : $0.65 \%$ to $1.32 \%$ ). In addition, extended-duration prophylaxis with enoxaparin increased the incidence of major bleeding ( $\mathrm{RD}=0.51 \%, 95 \% \mathrm{CI}: 0.12$ to 0.89 ) as well as total (major and clinically relevant non-major) bleeding $(\mathrm{RD}=2.37 \%, 95 \% \mathrm{CI}$ : $1.26 \%$ to $3.48 \%$ ). This led the ACCP to recommend against extended-duration thromboprophylaxis with enoxaparin in its guidelines. ${ }^{3}$

Thromboprophylaxis with either LMWH, UFH, or fondaparinux can be cumbersome because of the parenteral administration, erratic absorption, and altered clearance in patients with renal disease. Therefore, the direct oral anticoagulants (DOACs) apixaban, rivaroxaban, and betrixaban have been evaluated as alternatives to the parenteral agents ${ }^{5-7}$ for extended prophylaxis with DOACs beyond the standard 6-14 days in medically ill patients. So far, 3 Phase III trials have evaluated such extended-duration thromboprophylaxis with DOACs relative to short-duration prophylaxis with enoxaparin in this population: ${ }^{7}$ the ADOPT trial evaluating apixaban, ${ }^{5}$ the MAGELLAN trial assessing rivaroxaban, ${ }^{6}$ and the APEX trial examining betrixaban. ${ }^{7}$

Balancing the prevention of VTE with bleeding events presents a particular challenge as clinicians aim to reconcile the risk of 2 sets of adverse events (VTE and bleeding) to find a net clinical thromboprophylactic benefit. Herein, we first summarize these 3 pivotal Phase III trials. Second, we present the results of a meta-analysis of these trials on the efficacy and safety outcomes of DOACs as a class in extended-duration thromboprophylaxis for medically ill patients. We also compare our findings with those of 2 related but different meta-analyses. Third, we present a quantitative risk/benefit analysis of extended-duration thromboprophylaxis with DOACs versus short-duration prophylaxis with enoxaparin.

\section{Summary of clinical trials}

Study design, efficacy and safety outcomes, baseline characteristics, and clinical status of patients from the 3 Phase III trials are summarized in Tables 1 and 2.

The ADOPT trial evaluated the efficacy and safety of apixaban $2.5 \mathrm{mg}$ twice daily (up to 30 days) to short-duration thromboprophylaxis with subcutaneous (SC) enoxaparin 40 mg once daily (6-14 days). At day 30, VTE events occurred in $2.71 \%$ of patients treated with apixaban compared with
$3.06 \%$ in those who received enoxaparin (relative risk $[\mathrm{RR}]=0.87,95 \% \mathrm{CI}: 0.62$ to $1.23 ; P=0.44)$, indicating similar efficacy of both prophylaxis options in reducing VTE events. In terms of safety, apixaban was associated with higher major bleeding rates $(0.47 \%$ versus $0.19 \%$; $\mathrm{RR}=2.58,95 \% \mathrm{CI}: 1.02$ to $7.24 ; P=0.04)$. No differences were found between both prophylaxis arms with regard to clinically relevant bleeding $(2.67 \%$ versus $2.08 \%, \mathrm{RR}=1.28,95 \% \mathrm{CI}$ : 0.93 to 1.76 ; $P=0.12$ ). The all-bleeding rates were also comparable in both groups $(7.73 \%$ versus $6.81 \%$; $\mathrm{RR}=1.13,95 \% \mathrm{CI}: 0.95$ to $1.34 ; P=0.18$ ). The death rate was $4.1 \%$ in both groups. ${ }^{5}$

The MAGELLAN trial assessed the efficacy and safety of rivaroxaban $10 \mathrm{mg}$ once daily ( $35 \pm 4$ days) versus shortduration thromboprophylaxis with SC enoxaparin $40 \mathrm{mg}$ once daily (10 \pm 4 days). ${ }^{6}$ At day 35 , VTE events occurred in $4.4 \%$ of patients who received rivaroxaban compared with $5.7 \%$ of patients treated with enoxaparin ( $\mathrm{RR}=0.77,95 \% \mathrm{CI}: 0.62$ to $0.96, P=0.02$ ). However, clinically relevant bleeding (major bleeding and clinically relevant non-major bleeding events) occurred in $4.1 \%$ of patients in the rivaroxaban study arm compared with $1.7 \%$ of those in the enoxaparin $\operatorname{arm}(\mathrm{RR}=2.5$, 95\% CI: 1.85 to $3.25 ; P<0.001)$. Death from any cause was similar in both groups at $5.1 \%$ of rivaroxaban patients versus $4.8 \%$ of enoxaparin patients.

The APEX trial investigated the efficacy and safety of betrixaban, administered as a single loading dose of $160 \mathrm{mg}$ followed by $80 \mathrm{mg}$ once daily for 35-42 days versus shortduration thromboprophylaxis with enoxaparin (10 \pm 4 days). ${ }^{7}$ Efficacy and safety outcomes were evaluated in 3 pre-specified cohorts. Cohort 1 included patients with elevated D-dimer levels ( $62 \%$ of overall study population). Cohort 2 consisted of patients with elevated D-dimer levels and aged $\geq 75$ years $(91 \%$ of overall study population). Cohort 3 consisted of all patients in the study. ${ }^{7}$ In cohort 1 , VTE events occurred in $6.9 \%$ of patients who received thromboprophylaxis with betrixaban compared with $8.5 \%$ of those who were treated with enoxapa$\operatorname{rin}(\mathrm{RR}=0.81,95 \% \mathrm{CI}: 0.65$ to $1.00 ; P=0.054)$, which missed the statistical significance threshold of $<0.05$. In cohort 2 , the primary outcome occurred in $5.6 \%$ of betrixaban patients compared with $7.1 \%$ of enoxaparin patients $(\mathrm{RR}=0.80,95 \%$ CI: 0.66 to $0.98 ; P=0.03$ ), which was statistically significant. In cohort 3, the corresponding rates were $5.3 \%$ and $7.0 \%$, respectively ( $\mathrm{RR}=0.76,95 \% \mathrm{CI}$ : 0.63 to $0.92 ; P=0.006)$, which was also statistically significant. The rates of major bleeding in patients who received betrixaban were, by cohort, $0.6 \%$, $0.7 \%$, and $0.7 \%$, respectively, versus $0.7 \%, 0.6 \%$, and $0.6 \%$ in patients prophylacted with enoxaparin (all RRs crossed unity and all $P=$ non-significant). Death from any cause occurred 
Table I Study design and outcomes

\begin{tabular}{|c|c|c|c|}
\hline & ADOPT $^{5}$ & MAGELLAN ${ }^{6}$ & APEX $^{7}$ \\
\hline Sample size & 6758 & 8101 & 6850 \\
\hline Design & Randomized double-blind & Randomized double-blind & Randomized double-blind \\
\hline Intervention & Apixaban for 30 days & Rivaroxaban for $35 \pm 4$ days & Betrixaban for $35-42$ days \\
\hline Control & Enoxaparin for 6-14 days & Enoxaparin for $10 \pm 4$ days & Enoxaparin for 6-14 days \\
\hline Type of analysis & Superiority analysis & Superiority analysis & Superiority analysis \\
\hline Primary efficacy outcomes & $\begin{array}{l}\text { Composite of fatal or non-fatal PE, } \\
\text { symptomatic DVT, asymptomatic } \\
\text { proximal leg DVT, death related to } \\
\text { VTE }\end{array}$ & $\begin{array}{l}\text { Composite of asymptomatic } \\
\text { proximal DVT, symptomatic } \\
\text { proximal or distal DVT, symptomatic } \\
\text { non-fatal PE, death related to VTE }\end{array}$ & $\begin{array}{l}\text { Composite of asymptomatic } \\
\text { proximal DVT, symptomatic } \\
\text { proximal or distal DVT, symptomatic } \\
\text { non-fatal PE, death from VTE }\end{array}$ \\
\hline $\begin{array}{l}\text { Rate of the primary } \\
\text { efficacy outcomes during } \\
\text { extended-duration }\end{array}$ & Day 30: & Day 35: & $\begin{array}{l}\text { Cohort I: } \\
\text { Betrixaban } 6.9 \% \\
\text { Enoxaparin/placebo } 8.5 \%\end{array}$ \\
\hline thromboprophylaxis & $\begin{array}{l}\text { Apixaban } 2.7 \% \\
\text { Enoxaparin/placebo } 3.1 \%\end{array}$ & $\begin{array}{l}\text { Rivaroxaban } 4.4 \% \\
\text { Enoxaparin/placebo } 5.7 \%\end{array}$ & $\begin{array}{l}\text { Cohort 2: } \\
\text { Betrixaban } 5.6 \% \\
\text { Enoxaparin/placebo } 7.1 \% \\
\text { Cohort 3: } \\
\text { Betrixaban } 5.3 \% \\
\text { Enoxaparin/placebo } 7.0 \%\end{array}$ \\
\hline $\begin{array}{l}\text { Rate of the primary } \\
\text { efficacy outcomes } \\
\text { during short-duration } \\
\text { thromboprophylaxis }\end{array}$ & $\begin{array}{l}\text { Apixaban } 1.7 \% \\
\text { Enoxaparin } 1.6 \%\end{array}$ & $\begin{array}{l}\text { Rivaroxaban } 2.7 \% \\
\text { Enoxaparin } 2.7 \%\end{array}$ & $\begin{array}{l}\text { Betrixaban } 0.27 \% \\
\text { Enoxaparin } 0.34 \%\end{array}$ \\
\hline Safety outcomes & $\begin{array}{l}\text { Major bleeding, clinically relevant } \\
\text { non-major bleeding, and all bleeding } \\
\text { reported by investigators }\end{array}$ & $\begin{array}{l}\text { Composite of major bleeding or } \\
\text { clinically relevant non-major bleeding } \\
\text { events observed no later than } 2 \text { days } \\
\text { after administration of the last dose } \\
\text { of double-blind study medication }\end{array}$ & $\begin{array}{l}\text { Major bleeding at any point until } 7 \\
\text { days after the discontinuation of all } \\
\text { study medications }\end{array}$ \\
\hline $\begin{array}{l}\text { Rate of the safety outcomes } \\
\text { during extended-duration } \\
\text { thromboprophylaxis }\end{array}$ & $\begin{array}{l}\text { Major bleeding: } \\
\text { Apixaban } 0.47 \% \\
\text { Enoxaparin/placebo } 0.19 \% \\
\text { Major bleeding plus clinically-relevant } \\
\text { non-major bleeding: } \\
\text { Apixaban } 2.67 \% \\
\text { Enoxaparin/placebo } 2.08 \% \\
\text { All bleeding: } \\
\text { Apixaban } 7.73 \% \\
\text { Enoxaparin/placebo } 6.81 \%\end{array}$ & $\begin{array}{l}\text { Rivaroxaban } 4.1 \% \\
\text { Enoxaparin/placebo I.7\% }\end{array}$ & $\begin{array}{l}\text { Cohort I: } \\
\text { Betrixaban } 0.6 \% \\
\text { Enoxaparin/placebo } 0.7 \% \\
\text { Cohorts } 2 \text { and } 3 \text { : }\end{array}$ \\
\hline $\begin{array}{l}\text { Rate of the safety outcomes } \\
\text { during short-duration } \\
\text { thromboprophylaxis }\end{array}$ & $\begin{array}{l}\text { Major bleeding: } \\
\text { Apixaban } 0.25 \% \\
\text { Enoxaparin } 0.12 \% \\
\text { Major bleeding plus clinically-relevant } \\
\text { non-major bleeding: } \\
\text { Apixaban } 1.82 \% \\
\text { Enoxaparin } 1.37 \% \\
\text { All bleeding: } \\
\text { Apixaban } 5.34 \% \\
\text { Enoxaparin } 4.86 \%\end{array}$ & $\begin{array}{l}\text { Rivaroxaban } 2.8 \% \\
\text { Enoxaparin } 1.2 \%\end{array}$ & $\begin{array}{l}\text { Cohort 3: } \\
\text { Betrixaban I.37\% } \\
\text { Enoxaparin/placebo } 2.86 \%\end{array}$ \\
\hline
\end{tabular}

Abbreviations: DVT, deep vein thrombosis; PE, pulmonary embolism; VTE, venous thrombo-embolism.

in $5.7 \%$ of patients in the betrixaban group versus $5.8 \%$ of patients in the enoxaparin ( $P=$ non-significant). ${ }^{7}$ In contrast, when focusing on the composite of major or clinically relevant non-major bleeding, the rates in the betrixaban arms of the 3 cohorts were $3.1 \%, 3.2 \%$, and $3.1 \%$ versus $1.9 \%, 1.7 \%$, and
$1.6 \%$ in the enoxaparin arms of the cohorts. In cohort 1 , the RR was 1.64 (95\% CI: 1.13 to $2.37 ; P=0.009)$; in cohort 2 , the RR was 1.89 (95\% CI: 1.38 to $2.59 ; P<0.001)$; and in cohort 3, the RR was 1.97 (95\% CI: 1.44 to $2.68 ; P<0.001)$; all of which were statistically significant. 
Table 2 Patient demographics and clinical status

\begin{tabular}{|c|c|c|c|c|c|c|c|c|}
\hline & \multicolumn{2}{|l|}{ ADOPT } & \multicolumn{2}{|l|}{ MAGELLAN } & \multicolumn{2}{|l|}{ APEX } & \multicolumn{2}{|l|}{ Combined } \\
\hline & $\begin{array}{l}\text { Apixaban } \\
(N=3255)\end{array}$ & $\begin{array}{l}\text { Enoxaparin } \\
(\mathrm{N}=3273)\end{array}$ & $\begin{array}{l}\text { Rivaroxaban } \\
(N=4050)\end{array}$ & $\begin{array}{l}\text { Enoxaparin } \\
(\mathrm{N}=405 \mathrm{I})\end{array}$ & $\begin{array}{l}\text { Betrixaban } \\
(N=3759)\end{array}$ & $\begin{array}{l}\text { Enoxaparin } \\
(\mathrm{N}=3754)\end{array}$ & $\begin{array}{l}\text { DOAC } \\
(N=I \mid, 064)\end{array}$ & $\begin{array}{l}\text { Enoxaparin } \\
(\mathrm{N}=\mid I, 078)\end{array}$ \\
\hline Age, mean (SD) years & $66.8(12.0)$ & $66.7(12.0)$ & $7 I^{*}$ & $71 *$ & $76.6(8.46)$ & $76.2(8.31)$ & NR & NR \\
\hline Women (\%) & 50.0 & 51.80 & 44.40 & 47.30 & 54.60 & 54.20 & 49.67 & 51.10 \\
\hline \multicolumn{9}{|c|}{ Main disease on admission } \\
\hline Heart failure (\%) & 39.0 & 38.10 & 32.30 & 32.40 & 44.60 & 44.50 & 38.63 & 38.33 \\
\hline Respiratory failure (\%) & 37.10 & 37.10 & 27.30 & 28.70 & 11.90 & 12.60 & 25.43 & 26.13 \\
\hline Infection (\%) & 21.50 & 22.80 & 45.80 & 45.10 & 29.60 & 28.20 & 32.30 & 32.03 \\
\hline Ischemic stroke (\%) & NA & NA & 17.30 & 17.30 & 10.90 & 11.50 & 14.10 & 14.40 \\
\hline \multicolumn{9}{|l|}{ Risk factors for VTE } \\
\hline History of cancer (\%) & 9.60 & 9.80 & 17.30 & 16.70 & 12.40 & 11.80 & 13.10 & 12.77 \\
\hline History of VTE (\%) & 4.30 & 3.80 & 5.0 & 4.40 & 8.30 & 7.90 & 5.87 & 5.37 \\
\hline Age $\geq 75$ years $(\%)$ & 29.60 & 29.90 & 38.30 & 38.60 & 68.50 & 67.0 & 45.47 & 45.17 \\
\hline $\begin{array}{l}\text { Hormonal replacement } \\
\text { therapy (\%) }\end{array}$ & 1.50 & 0.80 & 1.20 & 1.20 & I. 10 & 0.80 & $\mathrm{I} .27$ & 0.93 \\
\hline
\end{tabular}

Notes: *Median reported only. NR, means age could not be calculated as one study reported age as median.

Abbreviations: DOAC, direct oral anti-coagulant; NA, not available; NR, not reported; VTE, venous thrombo-embolism.

\section{Meta-analysis of efficacy and safety outcomes of DOACs as a class}

Given the variation in efficacy and safety results of the 3 DOACs across the respective Phase III trials, we performed a meta-analysis to evaluate $6 \mathrm{VTE}$ and 3 bleeding outcomes for DOACs as a class. The VTE outcomes included were as follows: symptomatic VTE (including both symptomatic DVT and symptomatic PE), total VTE (symptomatic and asymptomatic), asymptomatic proximal DVT, symptomatic proximal or distal DVT, symptomatic non-fatal PE, and VTE-related death. The bleeding outcomes were: major bleeding, clinically relevant non-major bleeding, and clinically relevant bleeding. It should be noted that we had to calculate some outcomes as they were not specified in the trial reports.

\section{Methods}

Eligible studies were randomized clinical trials evaluating at least 1 of the DOACs apixaban, rivaroxaban, or betrixaban for extended-duration thromboprophylaxis in medically ill patients versus short-duration thromboprophylaxis with enoxaparin. Though we had already identified the 3 pivotal trials by monitoring their status on clinicaltrials.gov and in the literature, to assure completeness, we also searched PubMed, EMBASE, and the Cochrane Database of Systematic Reviews up to 15 March 2017. In addition, the reference lists of key articles were reviewed for additional citations. No additional trials were identified. Two reviewers (MA and SK) independently extracted data. Any disagreements were resolved by consensus or escalated to a third reviewer (IA). To estimate the pooled treatment effects, we calculated the Mantel-Haenszel random-effects risk ratios and corresponding 95\% CIs using the metan routine in STATA (version 14.2; StataCorp LLC, College Station, TX, USA). Heterogeneity was assessed by the $I^{2}$ statistic.

\section{Results}

Figures 1 and 2 show the forest plots for the VTE and bleeding outcomes, as well as the statistical parameters of interest. In the pooled analysis, extended-duration prophylaxis with DOACs was superior in efficacy over short-duration prophylaxis with enoxaparin with regard to symptomatic VTE (risk ratio $=0.63,95 \%$ CI: 0.46 to 0.88 ) and total VTE (risk ratio $=0.78,95 \%$ CI: 0.68 to 0.90 ). However, no statistically significant differences were found in efficacy between extended-duration prophylaxis with DOACs and short-duration prophylaxis with enoxaparin with regard to asymptomatic proximal DVT (risk ratio $=0.84,95 \% \mathrm{CI}$ : 0.70 to 1.01 ), symptomatic proximal or distal DVT (risk ratio $=0.60,95 \% \mathrm{CI}: 0.34$ to 1.06 ), symptomatic non-fatal PE (risk ratio $=0.67,95 \%$ CI: 0.41 to 1.09 ) and VTE-related death (risk ratio $=0.70,95 \%$ CI: 0.45 to 1.08 ).

On the safety side, prophylaxis with DOACs was associated with greater risks of major bleeding (risk ratio $=1.99$, 95\% CI: 1.08 to 3.65 ), clinically relevant non-major bleeding (risk ratio $=1.86,95 \%$ CI: 1.16 to 2.97 ), and the composite of clinically relevant bleeding (risk ratio $=1.84,95 \%$ CI: 1.27 to 2.68; Figure 2). 


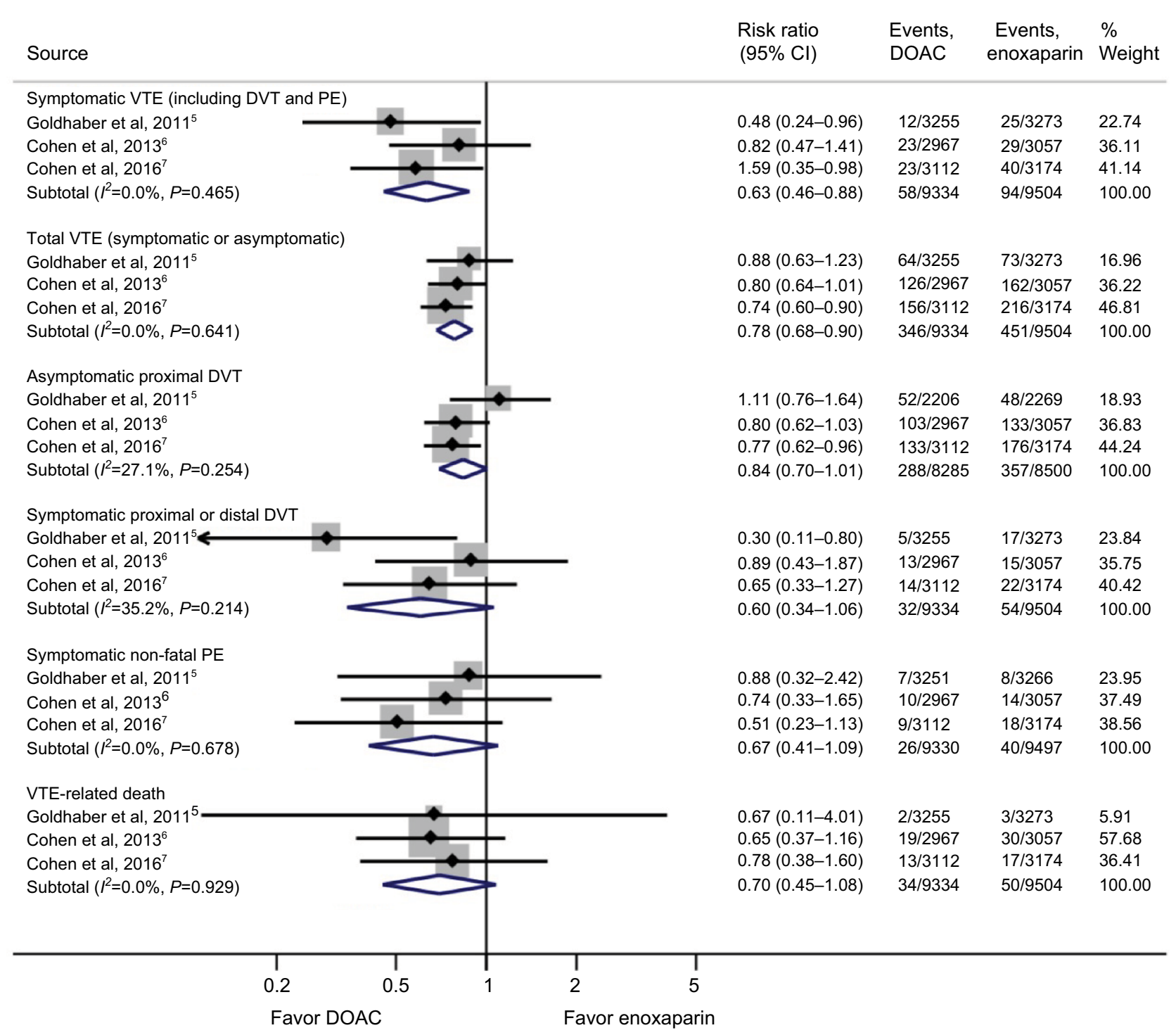

Figure I Meta-analysis results: efficacy outcomes.

Notes: Weights are from random effects analysis. risk ratio refers to the efficacy benefit of averting a VTE event when prophylacting with either DOACs or enoxaparin. risk ratio $<1.00$ with $95 \% \mathrm{Cl}<\mathrm{I} .00$ denotes that DOACs are prophylactically more efficacious, whereas risk ratio $>1.00$ with $95 \% \mathrm{Cl}>\mathrm{I} .00$ denotes that enoxaparin is prophylactically more efficacious than DOACs in averting a VTE. risk ratio with $95 \% \mathrm{Cl}$ limits $0.00<$ risk ratio estimate $>1.00$ denotes relative equivalence of DOAC and enoxaparin prophylaxis in averting VTE.

Abbreviations: DOAC, direct oral anti-coagulant; DVT, deep vein thrombosis; PE, pulmonary embolism; VTE, venous thromboembolism.

\section{Risk/benefit assessments of extended-duration DOAC versus short-duration enoxaparin thromboprophylaxis}

We conducted risk/benefit analyses for those metaanalysis results that were statistically significant. ${ }^{8}$ This included the 2 benefit outcomes of symptomatic VTE and total VTE and the 3 risk outcomes of major bleeding, clinically relevant non-major bleeding, and clinically relevant bleeding.

\section{Methods}

On the benefit side, we estimated the number of patients needed to treat (NNT) to achieve 1 additional reduction in VTE outcome. We first calculated the absolute risk reduction (ARR) and 95\% CI of prophylaxis with DOACs over prophylaxis with enoxaparin for the statistically significant VTE outcome of interest. The inverse of a given ARR and its $95 \% \mathrm{CI}$ yielded the NNT and its $95 \% \mathrm{CI}$ (NNT=1/ARR). On the risk side, we estimated the number of patients needed to harm $(\mathrm{NNH})$; that is, the number of patients who needed to be exposed to thromboprophylaxis with DOACs to cause 


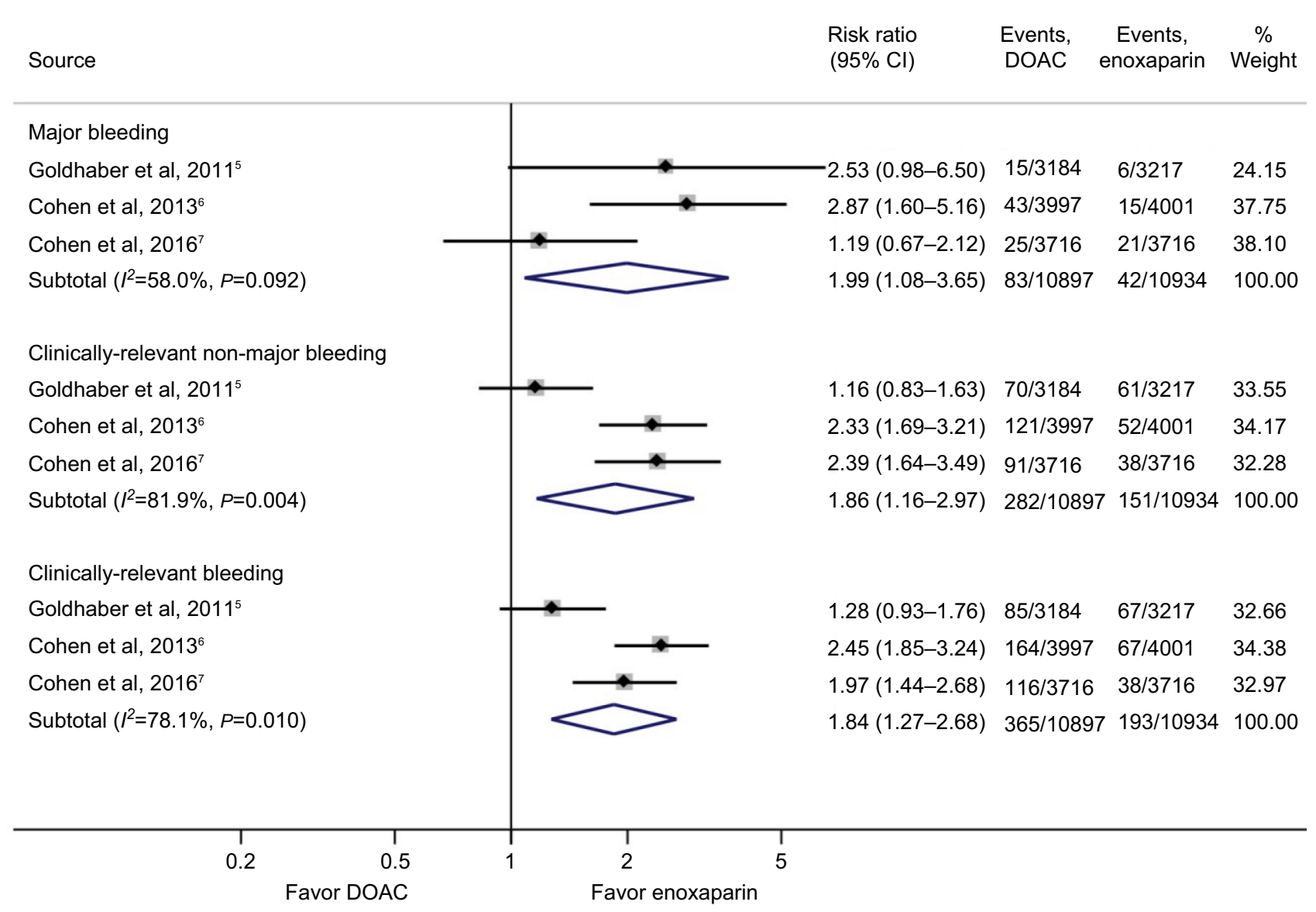

Figure 2 Meta-analysis results: safety outcomes.

Notes: Weights are from random effects analysis. risk ratio refers to the safety benefit of averting a bleeding event when prophylacting with either DOACs or enoxaparin. risk ratio $<1.00$ with $95 \% \mathrm{Cl}<1.00$ denotes that DOACs are prophylactically more efficacious, whereas risk ratio $>1.00$ with $95 \% \mathrm{Cl}>1.00$ denotes that enoxaparin is prophylactically more efficacious than DOACs in averting bleeding event. risk ratio with $95 \% \mathrm{Cl}$ limits $0.00<$ risk ratio estimate $>1.00$ denotes relative equivalence of DOAC and enoxaparin prophylaxis in averting bleeding events.

Abbreviation: DOAC, direct oral anti-coagulant.

a bleeding event of interest in 1 additional patient who otherwise would not have experienced this bleeding event. We calculated the absolute risk increase (ARI) and 95\% CI associated with prophylaxis with DOACs versus enoxaparin, and took the inverses $(\mathrm{NNH}=1 / \mathrm{ARI})$, to derive the $\mathrm{NNH}$ estimate and its $95 \%$ CI.

The risk/benefit was calculated by dividing the NNH by NNT. The NNH/NNT ratio $<1$ indicated more harm from a bleeding outcome relative to the benefit of a reduction in VTE outcome. Conversely, the value $>1$ indicated more VTE reduction benefit than the harm from a given bleeding outcome. ${ }^{8}$

\section{Results}

Table 3 summarizes the risk/benefit results. On the benefit side, for symptomatic VTE, the NNT was 276 patients (95\% CI: 165 to 1016) and for total VTE, the NNT was 105 patients (95\% CI: 66 to 253 ), indicating the numbers of patients who would need to be prophylacted to achieve 1 additional reduction in each of these VTE outcomes. On the risk side, for major bleeding, the NNH was 268 (95\% CI: 180 to 598), indicating the number of patients who would need to be exposed to extended prophylaxis with DOACs for 1 additional patient to experience a major bleeding episode. For clinically relevant non-major bleeding, the NNH was 86 (95\% CI: 66 to 126), indicating the number of patients who would need to be prophylacted with DOACs for 1 additional patient to experience such a bleeding. For the composite of clinically relevant bleeding, the NNH was 66 (95\% CI: 53 to 91), or the number of patients to be prophylacted with DOACs for 1 additional patient to experience a bleeding event.

In the risk/benefit assessment (Table 3 ), there was parity between major bleeding risk and symptomatic VTE averted $(\mathrm{NNH} / \mathrm{NNT}=0.97)$. As to total VTE, 2.56 fewer patients needed to be prophylacted with DOACs to avert 1 VTE episode for 1 additional patient to experience a major bleeding 
Table 3 Risk/benefit assessment for clinical outcomes with statistically significant results in the meta-analysis

\begin{tabular}{|c|c|c|c|c|c|c|c|c|}
\hline \multirow{3}{*}{$\begin{array}{l}\text { Benefit (thromboprophylaxis) of } \\
\text { DOACs over enoxaparin } \\
\text { Symptomatic VTE }\end{array}$} & \multicolumn{2}{|c|}{ Clinical outcome rates } & \multicolumn{3}{|c|}{$\begin{array}{l}\text { Absolute risk reduction by } \\
\text { DOACs (clinical outcomes) }\end{array}$} & \multicolumn{3}{|c|}{ Number-needed-to-treat } \\
\hline & \multirow{2}{*}{$\begin{array}{l}\text { Enoxaparin } \\
0.010\end{array}$} & \multirow{2}{*}{$\begin{array}{l}\text { DOAC } \\
0.006\end{array}$} & \multirow{2}{*}{$\begin{array}{l}\text { ARR } \\
0.004\end{array}$} & \multicolumn{2}{|c|}{$95 \% \mathrm{Cl}$} & \multirow{2}{*}{$\begin{array}{l}\text { NNT } \\
276\end{array}$} & \multicolumn{2}{|c|}{$95 \% \mathrm{Cl}$} \\
\hline & & & & 0.001 & 0.006 & & 165 & 1016 \\
\hline Total VTE & 0.047 & 0.037 & 0.010 & 0.004 & 0.015 & 105 & 66 & 253 \\
\hline \multirow[t]{2}{*}{$\begin{array}{l}\text { Harm (bleeding) of DOACs over } \\
\text { enoxaparin }\end{array}$} & \multicolumn{2}{|c|}{ Adverse event rates } & \multicolumn{3}{|c|}{$\begin{array}{l}\text { Absolute risk increase by } \\
\text { DOACs (adverse events) }\end{array}$} & \multicolumn{3}{|c|}{ Number-needed-to-harm } \\
\hline & Enoxaparin & DOAC & ARI & $95 \%$ & & NNH & $\mathbf{9 5 \%}$ & \\
\hline Major bleeding & 0.004 & 0.008 & 0.004 & 0.002 & 0.006 & 268 & 180 & 598 \\
\hline Clinically-relevant non-major bleeding & 0.014 & 0.026 & 0.012 & 0.008 & 0.015 & 86 & 66 & 126 \\
\hline Clinically-relevant bleeding & 0.018 & 0.033 & 0.015 & 0.011 & 0.019 & 66 & 53 & 91 \\
\hline $\begin{array}{l}\text { Risk-benefit assessment (NNH/NNT) } \\
\text { of DOACs over enoxaparin }\end{array}$ & $\begin{array}{l}\text { Major } \\
\text { bleeding }\end{array}$ & $\begin{array}{l}\text { Clinicall } \\
\text { non-maj }\end{array}$ & $\begin{array}{l}\text { elevant } \\
\text { bleeding }\end{array}$ & $\begin{array}{l}\text { Clinic } \\
\text { relev } \\
\text { bleed }\end{array}$ & & & & \\
\hline Symptomatic VTE & 0.97 & 0.31 & & 0.24 & & & & \\
\hline Total VTE & 2.56 & 0.82 & & 0.63 & & & & \\
\hline
\end{tabular}

Notes: The absolute risk reduction is the difference in the event rates for a given clinical outcome attributable to prophylaxis with DOACs versus enoxaparin; that is, the incremental benefit of DOAC over enoxaparin prophylaxis. The NNT is the number of patients to be prophylacted with DOACs to avoid a given clinical outcome in I patient (lower = better). The ARI refers to the difference in event rates for a given adverse event attributable to prophylaxis with DOACs versus enoxaparin; that is, the incremental harm of DOAC over enoxaparin prophylaxis. The NNH is the number of patients to be prophylacted with DOACs for I patient to experience the AE (higher = better). ARR, ARI, NNT, and NNH were calculated using www.statpages.info/ctab2x2.html. The risk/benefit ratio is the ratio of NNH to NNT. A value $<$ I indicates that the harm from a given $A E$ exceeds the clinical benefit of a given outcome; a value $>I$ indicates that the clinical benefit of a given outcome exceeds the harm from a given $A E$. Abbreviations: AE, adverse event; ARI, absolute risk increase; ARR, absolute risk reduction; DOAC, direct oral anti-coagulant; DVT, deep vein thrombosis; NNH, numberneeded-to-harm; NNT, number-needed-to-treat; PE, pulmonary embolism; VTE, venous thromboembolism.

event. ${ }^{8}$ However, the risks of clinically relevant non-major bleeding or the composite bleeding index of clinically relevant bleeding exceeded the thromboprophylactic benefit in terms of symptomatic VTE (NNH/NNT $=0.31$ and 0.24 , respectively) and total VTE averted (NNH/NNT $=0.82$ and 0.63 , respectively).

\section{Discussion}

Our meta-analysis indicates that extended-duration prophylaxis with DOACs instead of short-duration prophylaxis with enoxaparin in acutely ill medical patients is associated with a significant reduction in the risk of symptomatic VTE and total VTE (symptomatic or asymptomatic). However, it is not associated with a decrease in the risk of asymptomatic proximal DVT, symptomatic proximal or distal DVT, symptomatic non-fatal PE, and VTE-related death. This partial prophylactic benefit is further mitigated by the approximately 2 -fold increase in the risk of major bleeding, clinically relevant non-major bleeding, and clinically relevant bleeding compared with short-duration prophylaxis with enoxaparin.

Importantly, while the results of our meta-analysis are consistent with those from a meta-analysis recently published as a Letter by Tao et al, ${ }^{9}$ they also extend the latter significantly. These authors limited their efficacy analyses for extended thromboprophylaxis to total thromboembolic events and to symptomatic thromboembolic events. This limited their meta-analysis results to findings favoring extended-duration prophylaxis with DOACs. Our analysis adds the critical findings that, compared with short-duration enoxaparin prophylaxis, thromboprophylaxis with DOACs does not reduce the risk of asymptomatic proximal DVT, symptomatic proximal or distal DVT, symptomatic non-fatal PE, and VTE-related death. These are VTE events that, clinically, are highly relevant in the care of acutely ill medical patients and it is unclear why these were not included in Tao et al's meta-analysis. It should be noted that minor differences were found between the $2 \mathrm{RR}$ estimates reported by Tao et al and our corresponding estimates. This is due to the variations in the reported numbers of the individual outcomes from the original studies.

As to safety data, Tao et al reported an RR of 1.74 (95\% CI: 1.05 to 2.90) for an NNH of 60 for the composite of clinically relevant bleeding events and an RR of 1.71 (95\% CI: 1.07 to 2.75 ) and associated NNH of 417 for the total major bleeding events. Here too, slight differences were found in the estimates due to the variations in extracting such events from the original trials. Of concern, and also for unclear reasons, Tao et al omit clinically-relevant non-major bleeding. We provide meta-analytic evidence of a significantly increased risk as well.

Our safety results are consistent with those from a metaanalysis by Liew et al published even more recently. ${ }^{10}$ This 
meta-analysis included the 3 studies on extended-duration prophylaxis with DOACs that were included in our review. It also included the EXCLAIM trial comparing short-duration with extended-duration prophylaxis with enoxaparin ${ }^{4}$ in hospitalized acutely ill medical patients. In total, 34,068 patients from 4 randomized clinical trials were included in Liew et al's analysis. Extended-duration thromboprophylaxis with DOACs or enoxaparin was associated with a 2-fold increase in the risk of major bleeding compared with short-duration thromboprophylaxis with enoxaparin. Similar to our results, Liew et al found no difference between extended-duration thromboprophylaxis and short-duration thromboprophylaxis in terms of VTE-related death. Conversely, they noted a $48 \%$ reduction in the risk of symptomatic proximal or distal DVT. In addition, a 39\% reduction in the risk of symptomatic nonfatal PE was observed. As our meta-analysis did not detect significant increases in either symptomatic proximal or distal DVT, and symptomatic non-fatal PE, Liew et al's significant findings for these 2 efficacy outcomes are attributed to the addition of the EXCLAIM trial to the meta-analysis.

Apart from minor differences due to variation in statistical analysis methods, our meta-analysis confirms the incremental risk for major and clinically relevant non-major bleeding events. It should be noted that the 3 trials differed somewhat in their respective definitions of the safety outcomes evaluated. Notwithstanding, our, Tao et al's and Liew et al's metaanalyses underscore the increased bleeding risks associated with extended-duration DOAC prophylaxis.

While Tao et al did refer to a risk/benefit analysis, they only provided a qualitative statement that extended prophylaxis with DOAC offers a "less-than-ideal risk-benefit ratio." What differentiates our evaluation of the benefits relative to the risks of DOAC prophylaxis is that we conducted a formal risk/benefit analysis. The reduction in total VTE events with extended-duration thromboprophylaxis with DOACs outweighs the increased risk of major bleeding events. The reduction in symptomatic VTE is at par with major bleeding risk. However, major bleeding events are less frequent than clinically relevant non-major bleeding events and clinically relevant bleeding events in general. The higher incidence of the latter 2 bleeding indices outweigh the reduction in symptomatic and total VTE achieved with extended prophylaxis with DOACs. Considering also that such prophylaxis had no VTE benefit over short-duration enoxaparin on 4 other types of VTE-related events raises significant concerns about this prophylaxis option.

DOACs have been used successfully for extended-duration thromboprophylaxis post-hospitalization in orthopedic and surgical patients without exposing them to an increased risk of bleeding. ${ }^{11}$ Of the 3 DOACs that have been evaluated for extended-duration thromboprophylaxis in medically ill patients, neither rivaroxaban nor apixaban is US Food and Drug Administration (FDA) approved for this indication. Betrixaban was recently approved by the FDA for this indication. This is perhaps surprising considering that the APEX pivotal trial did not find extended prophylaxis with this agent to be superior to short prophylaxis with enoxaparin in the primary analysis cohort (subjects with elevated D-dimer); and that superiority was observed only in the exploratory followon analyses of patients with elevated D-dimer and aged $\geq 75$ years (cohort 2) and in the overall study population (cohort 3 ).

It was only in the MAGELLAN trial of rivaroxaban that a superior benefit of extended-duration thromboprophylaxis with a DOAC was observed. The ADOPT trial of apixaban did not find extended prophylaxis with apixaban to be superior. In addition, both agents were associated with a higher risk of bleeding. On the other hand, betrixaban seemed to have a better safety profile than rivaroxaban and apixaban. The rates of major bleeding in the betrixaban and enoxaparin groups were comparable across the cohorts. Interestingly, extendedduration thromboprophylaxis with betrixaban showed a net clinical benefit in all patients (i.e., cohort 3$)(\mathrm{RR}=0.78 ; 95 \%$ CI: 0.65 to $0.95 ; P=0.01$ ), defined as a composite of the primary efficacy outcome and the primary safety outcome. These conflicting results from the respective Phase III trials may be due to variations in the risk of VTE and bleeding among the patients included in these trials. While the inclusion and exclusion criteria were relatively similar in terms of minimum age (40 years), length of hospitalization, and the presence of at least 1 VTE risk factor, there was some variation in the distribution of VTE risk factors in general, as well as risk factors for bleeding.

When aggregated into our meta-analyses, a clearer pattern of the efficacy and safety of the 3 DOACs as a class become evident. These analyses showed a reduction in the risk of symptomatic VTE and total VTE in medically ill patients receiving extended-duration thromboprophylaxis with DOACs when compared with patients receiving short-term prophylaxis with enoxaparin. This is an important finding, supported also by the meta-analysis by Tao et al. ${ }^{9}$ However, these agents did not reduce the risk of asymptomatic proximal DVT, symptomatic proximal or distal DVT, symptomatic non-fatal PE, and VTE-related death events, all of which are clinically significant outcomes. The meta-analysis by Liew et $\mathrm{al}^{10}$ yielded significant risk reduction estimates for symptomatic proximal or distal DVT and symptomatic non-fatal 
PE. This was in an analysis that included the EXCLAIM trial of extended-duration versus short-duration prophylaxis with enoxaparin. Hence, if extended-duration prophylaxis has a (partial) benefit, it may not be with DOACs as the agent but with enoxaparin. More importantly, our pooled analysis showed a consistent increase in the risk of all the evaluated safety outcomes (i.e., major bleeding, clinically relevant non-major bleeding, and clinically relevant bleeding). This increased risk in bleeding outcomes was also reported in both Tao et al's and Liew et al's analyses, which reported significant increases in the risk of both major and total bleeding events. ${ }^{9,10}$

The limited thromboprophylactic effect of DOACs is mitigated by the approximately 2-fold increase in the risk of major bleeding and/or clinically relevant non-major bleeding. This may make extended-duration thromboprophylaxis with DOACs a less favorable, and likely a less cost-effective, option than short-duration thromboprophylaxis with enoxaparin in hospitalized acutely ill medical patients.

To our knowledge, our formal quantitative risk/benefit analysis is the first for extended thromboprophylaxis in medically ill patients with DOACs as a class. This selective, if not constrained, efficacy needs to be considered in light of the increased bleeding risk associated with, in particular apixaban and rivaroxaban. From a risk/benefit point of view, the risk of major bleeding is balanced relative to the effect on symptomatic VTE, and the effect on total VTE outweighs the risk of major bleeding. However, as far as (the much more common) clinically relevant non-major bleeding is concerned, the risk for such bleeding episodes outweighs the efficacy benefit in terms of symptomatic and total VTE. This conclusion also prevails when this type of bleeding is combined with major bleeding into the composite of clinically relevant bleeding. Considering also the lack of efficacy on 4 other VTE outcomes, as revealed in our meta-analysis, the bleeding risk offsets the clinical benefit of extended prophylaxis with DOACs.

The ACCP guidelines on the prevention of VTE in nonsurgical patients recommend against extended-duration thromboprophylaxis and this recommendation was based on results from the EXCLAIM trial. These guidelines have not been updated since 2012. Our findings validate this recommendation in principle; however, a formal update by the ACCP incorporating DOACs based on our results, as well as those from the Tao et $\mathrm{al}^{9}$ and Liew et $\mathrm{al}^{10}$ reviews, is indicated.

Future studies should focus on patients at high risk for VTE and exclude patients with elevated bleeding risk. This may lead to a targeting of extended-duration thromboprophylaxis with DOACs as well as enoxaparin to patients with dual VTE and bleeding risk. This will reveal who might benefit from which agents, why, and how. The ongoing MARINER study ${ }^{12}$ might answer the question of whether extended-duration thromboprophylaxis with DOACs is both safe and effective in medically ill patients after hospital discharge. We recommend that future studies include the 6 VTE efficacy outcomes (symptomatic VTE, total VTE, asymptomatic proximal DVT, symptomatic proximal or distal DVT, symptomatic non-fatal PE, and VTE-related death) and the 3 bleeding outcomes (major bleeding, clinically relevant non-major bleeding, and clinically relevant bleeding). This will permit a better differentiation of both the efficacy and safety outcomes of thromboprophylaxis regimens.

In summary, while there are efficacy signals with regard to extended DOAC thromboprophylaxis in medically ill patients, these may be limited to specific risk categories of patients and specific types of VTEs. The increased risk of bleeding needs to be fully appraised and reconciled in a formal risk/benefit analysis to guide clinical practice. At this time, the evidence of safe and effective extended-duration thromboprophylaxis with DOACs in this population is inconclusive.

\section{Disclosure}

The authors report no conflicts of interest in this work.

\section{References}

1. Heit JA, Spencer FA, White RH. The epidemiology of venous thromboembolism. J Thromb Thrombolysis. 2016;41(1):3-14.

2. Amin AN, Varker H, Princic N, Lin J, Thompson S, Johnston S. Duration of venous thromboembolism risk across a continuum in medically ill hospitalized patients. J Hosp Med. 2012;7(3):231-238.

3. Kahn SR, Lim W, Dunn AS, et al. Prevention of VTE in nonsurgical patients: antithrombotic therapy and prevention of thrombosis, 9th ed: American College of Chest Physicians evidence-based clinical practice guidelines. Chest. 2012;141(2 Suppl):e195S-e226S.

4. Hull RD, Schellong SM, Tapson VF, et al. Extended-duration venous thromboembolism prophylaxis in acutely ill medical patients with recently reduced mobility: a randomized trial. Ann Intern Med. 2010;153(1): $8-18$.

5. Goldhaber SZ, Leizorovicz A, Kakkar AK, et al. Apixaban versus enoxaparin for thromboprophylaxis in medically ill patients. $N$ Engl $J$ Med. 2011;365(23):2167-2177.

6. Cohen AT, Spiro TE, Büller HR, et al. Rivaroxaban for thromboprophylaxis in acutely ill medical patients. $N$ Engl J Med. 2013;368(6):513-523.

7. Cohen AT, Harrington RA, Goldhaber SZ, et al. Extended thromboprophylaxis with betrixaban in acutely ill medical patients. $N$ Engl J Med. 2016;375(6):534-544.

8. Curtin F, Schulz P. Assessing the benefit: risk ratio of a drug - randomized and naturalistic evidence. Dialogues Clin Neurosci. 2011;13(2): 183-190. 
9. Tao D, Bien J, DeLoughery T, Shatzel J. Extended thromboprophylaxis with direct oral anticoagulants for medical patients: a systematic review and meta-analysis. Blood 2017;129(5):653-655.

10. Liew AY, Piran S, Eikelboom, JW, Douketis JD. Extended-duration versus short-duration pharmacological thromboprophylaxis in acutely Ill hospitalized medical patients: a systematic review and metaanalysis of randomized controlled trials. J Thromb Thrombolysis. 2017;43(3):291-301.
11. Falck-Ytter Y, Francis CW, Johanson NA, et al. Prevention of VTE in orthopedic surgery patients. Chest. 2012;141(2 Suppl): e278S-e325S

12. Raskob GE, Spyropoulos AC, Zrubek J, et al. The MARINER trial of rivaroxaban after hospital discharge for medical patients at high risk of VTE. Design, rationale, and clinical implications. Thromb Haemost. 2016;115(6):1240-1248.

\section{Publish your work in this journal}

The Journal of Blood Medicine is an international, peer-reviewed, open access, online journal publishing laboratory, experimental and clinical aspects of all aspect pertaining to blood based medicine including but not limited to: Transfusion Medicine; Blood collection, Donor issues, Transmittable diseases, and Blood banking logistics; Immunohematology; Artificial and alternative
Dovepress

blood based therapeutics; Hematology; Biotechnology/nanotechnology of blood related medicine; Legal aspects of blood medicine; Historical perspectives. The manuscript management system is completely online and includes a very quick and fair peer-review system. Visit http://www.dovepress.com/ testimonials.php to read real quotes from published authors. 